the skin of the chin became erythematous. Later on the thick scales become loosened (process of exfoliation) and the lip underneath it is dry, glazed and at times fissured. I never found, as in Duhring's cases, that the disease was associated with a depressed state of the nervous system. Seborrhea of the scalp was not associated with any one of my cases. Clinically the disease is closely allied to Paget's disease (eczema of the nipple). Like the latter disease, it may start with a sclerotic eczema; later it may assiume the form of a dry scaly or branny crustation affecting the entire surface of the lower lip, which is darker colored, firmer and less pliant and elastic than its upper fellow. It apparently. has all the phases of eczema of the nipple and at times, like that affection, may become malignant. Perhaps in many a case of epithelioma of the lower lip the initial symptoms were the same as found in cheilitis exfoliativa. In Jamieson's case of cheilitis exfoliativa the thickening of the prickle-cell layer was so well marked that Leith thought it to be a mild form of epithelioma.

Little, however, is known of the pathology of the disease. No pathogenic microbe was ever isolated from a case, though attempts have been made in that direction. Though Dr. Hyde recognizes this disease as an instance of infective folliculitis, Dr. Heidingsfeld was right when he wrote me:

"Researches in this direction, as far as I am able to determine, are inclined to show that parasitology is rather accidental than causal in nature."

From my own observation I am forced to look on cheilitis exfoliativa as a clinically very important and pathologically most interesting form of keratosis, as found in eczema of the nipple or in other dermatoses in which excessive epidermis formation and cornification are the chief features. Whether this process is primarily a hyperplasia of the rete with induced secondary changes, or whether it originates as an inflammation of the papillary layer of the corium, producing cell infiltration and vascular dilatation, is only a matter of speculation.

Though therapeutic results in former years have not been the most gratifying, the latest reports are very encouraging. Mild antiseptics and the $x$-ray, if they did not accomplish a radical cure, have greatly benefited the disease. Dr. Hyde had best success with very cautious use of the $x$-ray and local antiseptics. Dr. Gilchrist asserts that the $x$-ray treatment is the most efficacious. He applies enough to produce a reaction. In two private cases he used the $x$-ray and the result was a cure in both instances. Pure carbolic acid was used by him in one case with great benefit but no cure. In my own cases I used different methods, and the best way to describe them is to give a summary of my cases up to date :

\section{REPORTS OF CASES.}

CAse 1.-Patient.-W. P., aged 39, was referred to me by Dr. T. Kinnard of Lexington, Ky. He was a farmer and stockraiser. His family history was good. He denied ever having syphilis, but had suffered from leucokeratosis buccalis for over five years. While the patient was sent to me for leucokeratosis buccalis only, his lower lip had a typical form of cheilitis exfoliativa. Under 15 per cent. solution of nitrate of silver by cataphoresis the lip got entirely well, while the leucokeratosis buccalis persisted, though greatly improved.

Case 2.-Patient.-H. F., a local dry-goods merchant, aged 46, consulted me in March, 1907. His family history was good. He had never had any venereal disease. He was an inveterate smoker. Within the last two years his lower lip had begun to feel tight and itchy. At first he thought he had chapped lips, but when he noticed exudation, crustation and exfoliation, he consulted several physicians and one of them pronounced the growth malignant. On examination I found it to be a usual type of cheintis exfoliativa. The mucous and salivary glands of the mouth were not affected. After fourteen $x$-ray treatments the patient was discharged cured. I saw him two weeks ago and not a sign of the disease was noticeable except that the skin on the lower lip was of darker color than the upper lip.

CASE 3.-Patient.-S. H. R., Shepherdsville, Ky., aged 35, was referred to me by Dr. W. Boggess. The patient's family history was good. He had always enjoyed good health. The symptoms were identical with those of Case 2, except that exfoliation was more pronounced. The patient was seen by Dr. Heidingsfeld, who pronounced the disease lupus erythematosus. The examination was made in the evening and was a hasty one. As the patient could not come to my office regularly I applied a 15 per cent. solution of nitrate of silver, followed by Lassar's paste (the one with salicylic acid) daily. Later on 1 used the $x$-ray. The patient imoroved.

CASE 4.-Patient.-A whisky drummer, aged 48 , referred to me by Patient 2 . It is a peculiar thing that patients with a certain disease always know people suffering from the same affection. The patient had nothing of importance ip the medical history except that he suffered from rheumatism. He complained of dryness in the mouth and contraction of the lower lip. The symptoms were the same as in all previous cases except that the muciparous glands were more involved, the exudation and crusting more pronounced. As the patient greatly objected to $x$-ray exposures, I used tincture of iodin by cataphoresis and Iassar's paste as a daily application. The patient showed great improvement.

In addition to the foregoing cases, two more cases were reported to me, one by Dr. W. Boggess and one by Dr. F. T. Fort, both of this city.

How long the relief or cure may be expected to last I can not say. There is no doubt in my mind that some cases will relapse in spite of energetic and seemingly successful treatment. When the true pathology of the disease is established we may not have to work in the dark, as we do now. For the present all attempts to arrive at the real pathologic basis have amounted to naught.

\section{THE PIGMENTATIONS OF THE MUCOUS MEM. BRANE OF THE MOUTH.* \\ HENRY G. ANTHONY, M.D. \\ Professor of Skin and Venereal Diseases, Chicago Policlinic. CHICAGO.}

The pigmentations of the mucous membrane of the mouth have not been sufficiently studied. In many instances I have noted that histories of reported cases, complete in other respects, were lacking in the simple statement that pigmentations of the mucous membrane of the mouth were present or absent.

The diseases of the mucous membrane of the mouth were made the subject of a symposium at the twentyeighth annual meeting of the American Dermatological Association without the pigmentations being mentioned in any of the papers presented or in the discussion. Our knowledge of pigmentations of the buccal cavity is meager, partly because they are rare and partly because they are not sought for in patients presenting pigmontary lesions of the skin.

Dentists inform me that they often notice pigmentations of the mouth without considering their signifi-

* Read in the Section on Cutaneous Medicine and Surger of the American Medical Association, at the Fifty-ninth Annual Session, held in Chicago, June, 1008. 
cance. It is only throngh the combined efforts of many observers that our knowlerge of a subject which has attracted so little attention as has this, can be augmented.

With the hope of stimulating my colleagues to search constantly for pigmentations of the mucous membrane of the mouth and also to induce them to report their cases, I venture to present what little I may on the subject.

\section{CONGENITAL PIGMENTATION.}

The most common form of congenital pigmentation of the skin is the soft mole which may be simply a pigmentation of the skin or which may present itself as a mammillated nodule with or without pigmentation and hairy growth. Oppenheim ${ }^{1}$ has reported a case of soft mole affecting the conjunctiva of the eyball and extending even over the cornea, but I find no cases on record in which soft moles were present in the mucous membrane of the mouth. Fven in cases in which the cutaneous surface was studded with pigmentary moles, as in the cases reported by Danlos, the mucous membrane of the mouth was free from moles.

In spite of the negative literature, I am convinced that such growths occur in the mucous membrane of the mouth. I have observed one case.

'I'he patient was a woman, sixty years of age. All her life she had had a nodule of the mucous membrane of the hard palate, situated in the middle line of the roof of the mouth midway between the teeth and the soft palate. It had steadily increased in size in recent years. At the time of observation it was a flattened elevated mammillated tumor the size and shape of a lima bean and not pigmented. There were a few pigmentary moles of the skin present.

Reasoning a priori, if pigmentary soft moles occur in the mucous membrane of the mouth, we should expect them to present a darker shade of pigmentation than corresponding skin lesions because nearly all pigmentations of mucous membranes are darker than analogous cutaneous chromatoses. They would usually be melanotic. We should not expect that pigmentary moles would always be present at the time of birth, for the reason that they and many other developmental defects of the skin, such as benign cystic epithelioma, frequently present themselves dinically for the first time in adult life. Further, we should expect endotheliomas to develop in some cases in such areas of pigmentations.

Roy $^{2}$ has reported a case of melanosis of the palate which, after existing twenty years, became sarcomatous. The microscopic appearance which the growth presented in this case was that of an endothelioma or what Unna calls a nevo-carcinoma. As the endothelioma is a special form of malignant disease which usually develops on moles, it is extremely probable that the melanosis present in this case for twenty years prior to the appearance of the malignant disease was a mole.

Whitfield $^{3}$ showed a woman with anomalous pigmentations of the mucous membrane of the month which he did not believe were moles because they did not date from childhood. These pigmentations may not have been moles, but the reason he assigned is entirely insufficient to exclude this possibility of diagnosis.

The pigmentations of xeroderma pirmentosum affect the vermilion border of the lips (Nicolas' case) but they have not been observed in the mouth.

1. Deutsch. med. Wchnschr.. 1903, No. 8.

2. Lalyngoscope, 1907 , p. 868 .

3. Brit. Jour, Dermat.. 1907, p. 203.

4. Nicolas: Ann, de Del'mat. et de Syph., 1906, p. 537.
The fibroma molluscum tumors of von Recklinghausen's disease frequently occur in the mouth, but the pigmentations affecting the mucous membrane must be quite rare, as they have not been present in any of my cases, and the only mention of them in recent literature is the report by Oddo, ${ }^{5}$ who describes them in two cases as well-defined areas of pigmentation affecting various parts of the mucous membrane and resembling the pigmentations which may be seen in the mouth of dogs.

\section{ACQUIRED PIGMENTATION.}

Traumatic.-Where injury produces hemorrhage into the mucous membrane, pigmentations may remain long after the effusion of blood has been absorbed. It is possible that such pigmentations may be permanent, but ordinary injury to the mucons membrane from rough teeih or other mechanical or chemical irritation does not cause pigmentation.

Addison's Disease.-The pigmentations of the mucous membrane of the mouth in this disease are usually not the same shade of bronze-color as is the skin, but consist of circumscribed areas of melanotic pigmentation. They are rarely absent and are of great diagnostic importance.

Akanthosis Nigricans.--The skin lesions of this disease are warts and pigmentations. The mouth is seldom free from lesions, but the lesions are not pigmentated, they are papillomatous and warty excrescences.

Arsenical Pigmentations.-Although arsenic frequently causes cutaneous pigmentations, there are no cases on record of the drug producing pigmentations of the mouth. Audry reported a case of pigmentation of the mucous membrane of the mouth caused by arsenic in 1896 , but subsequently on postmortem examination it was found that the patient had Addizon's disease and a note correcting the error was published in 1898 .

Jichen Planus.-On disappearing this disease leaves brown or slate-colored pigmentations of the skin. The disease usually affects the mucous membrane of the mouth, and within recent times Dubreuilh, ${ }^{7} \mathrm{Hyde}^{8}$ Lieberthal, ${ }^{9}$ and others have described the mouth lesions of this disease, but none of these authorities mention pigmentations of the mucous membrane of the mouth as lesion relics. In none of the cases that $I$ have had the opportunity to examine were there pigmentations present. I have examined one patient who was rarely free from buccal lesions during ten years and still there were no pigmentations present. Danlos has published a report of a case in which there was one large plaque of slate-colored pigmentation present. There was doubt as to whether the pigmentation was caused by lichen planus; it might have antedated the disease.

Scleroderma.-Stelwagon emphasizes the fact that pigmentation is frequently a lesion relic in scleroderma. Audry ${ }^{10}$ has reported a case of scleremia (a term used to designate those cases in which the disease extends much deeper than the skin producing a rigidity of the muscles) in which ill-defined plaques of pigmentations were present in the mucous membrane of the cheeks.

Phthiriasis.-Thibierge ${ }^{11}$ and a number of others have observed melanotic pigmentations of the mucous mernbrane of the mouth in cachectic subjects with

5. Ann. de Dermat. et. de Syph., 1906, p. 803

6. Ann. de Dermat. et de Syph., 1898, p. 538

7. Ann. de Dermat. et de Syph., 1903, p. 123.

8. Jour. Cut. Dis. and Syph., 1903, p. 105.

9. Lleberthal, David: Lichen Planus of the Oral Mucosa, The

Journal A. M. A., Feb. 16, 1907, xlviii, 559.

10. Ann. de Dermat. et de Syph., 1906, p. 972

11. Ann. de Dermat. et de Syph., 1892, p. 734 
cutaneous brown pigmentations. The fact that such buccal pigmentations occur only in cachetic individuals suggests the thought that hemochromatosis is the cause of such pigmentations rather than pediculi per se. This possibility of diagnosis has been excluded by the absence of iron in excised tissue of the mucous membrane in the case of Le Play and Dehu. ${ }^{12}$ Osler ${ }^{13}$ says that whenever hemochromatosis, either with or without diabetes, is suspected, the correctness of the diagnosis intra vitam will be made much more probable by removal of portions of the pigmental skin and the finding (by the potassium ferrocyanid test) of iron-containing pigment in the cells of the sweat glands and of the ochre-yellow in the muscle fibers of any blood ressels that may be present by the use of hemofuschin. That pigmentation is actually caused by pediculi is shown by the fact that Pediculi pubis cause blue pigmentations of the skin, so that, with hemochromatosis excluded, it is extremely probable that Pediculi corporis produce brown pigmentations of the skin and black pigmentation of the mucous membrane of the mouth. Cutaneous brown pigmentation will quickly disappear in these cases by the use of bichlorid baths, the method formerly employed to differentiate certain cases from possible Addison's disease. Hemochromatosis produces pigmentation of the skin, but no special attention has been paid to the mucous membrane of the mouth.

Anomalous Pigmentations. - I include in this class all pigmentations of the mucous membrane of the mouth which can not be assigned to any of the preceding disorders. They constitute the largest number. These pigmentations are almost invariably located in the mucous membrane of the lips. Patients are frequently ignorant of their presence. These are usually well-defined areas of black pigmentation. I have not observed them in healthy individuals. I have observed these plaques on the lips of patients suffering from gastrointestinal autointoxication, diabetes and neurasthenia. 02 State Street.

\section{ABSTRACT OF DISCUSSION.}

Dr. Willia Ar A. Puser, Chicago: The subject of diseases of the mucous membrane of the mouth, including the pigmentations, may be called almost a terra incognita, and anything that tends to summarize what we know about the subject is extremely useful. I have been watching pigmentary lesions of the mouth and have observed them chiefly with the view of trying to ascertain the reasons for their occurrence. I know that frequent references to the pigmentation of the mucous membrane in pediculosis have been made, but $I$ have never been able to understand the mechanism of its production. Nor have $I$ ever been able to find it, in spite of the fact that I have rather a large clientèle among the classes who suffer from pediculosis. Has any one present ever seen it? Dr. Anthony referred to the pigmentation on the inner surface of the lips occurring occasionally in neurotic individuals. I showed him such a case about two years ago. The patient, an extremely neurasthenic woman, developed spots of pigmentation on the inner surfaces of the lips. The lesions subsequently disappeared and have never recurred. Dr. Anthony referred me to similar cases in French literature.

Dr. H. G. Anthony, Chicago: I have never seen pigmentation in pediculosis, although constantly on the lookout for it, almost from the time $I$ began to practice medicine. The condition is so thoroughly accepted by French writers, however, and they have taken such pains to exclude other causes that I think it is fairly well established. The pigmentations of the mucous membrane of the mouth in neurasthenia are not so infrequent. They occur mostly on the lips.

12. Ann de Dermat. et de Syph., 1906

13. Modern Medicine, i, p. 756 .

\section{CRITERIA AND STANDARDS IN INFANT FEEDING.}

THOMAS GRANT ALLEN, A.M., M.D.

Professor of Diseases of Children, Post-Graduate Medical School. CHICAgO.

The criteria are all those signs and symptoms in the behavior of the infant by which we judge of the sufficiency and suitability of its food. By standards are meant the more or less fixed quality and quantity of the food and its various constituents. While the quality of the food, such as its cleanness, freshness, etc., is of prime importance, yet in this article it will be taken for granted that the quality of the food is all that can be desired, and therefore in the discussion of standards I shall deal only with their quantitative aspect.

\section{THE VARIOUS CRITERIA.}

If the baby is uncomfortable and fretful after being fed, and all possible external causes of discomfort have been eliminated, the probability is that there is something wrong with the food. If the discomfort comes immediately after feeding, the quality of the food may be all that is desired, but the quantity is likely to be at fault, either deficient or excessive, whereas, if the discomfort comes some time after feeding. the likelihood $i \approx$ that the quality or character of the food is not suitable for that particular baby.

The normal healthy young infant usually falls aslecp after being fed. If it does not do so, there is usually something wrong, and that something may be the food, its quantity, quality or suitability. A normal baby may cry from some cause or causes other than the food, but in a large proportion of the cases the feeding is at fault. The normal healthy baby will have a normal stool, homogeneous, mustard-yellow in color, of a not unpleasant odor, a salve-like consistence and free from admixture with curds or mucus.

The healthy baby will gain in weight in a certain pretty well defined way, ${ }^{1}$ that is, the first three months it will gain about half a pound a week or an ounce a day, the next three months the gain being not so. rapid, about a quarter of a pound a week, half an ounce a day or an ounce every two days. With this gain in weight should go a gain in length, a gain in strength and activity and a general development. By reference to Table 1 it will be seen that the average gain in length is one inch a month for the first four months, and thereafter half an inch a month until the end of the first year.

TABLE 1.-Showing Approximately the Weight and Height of the Baby Dering the First Year axd the Gain in Gach.

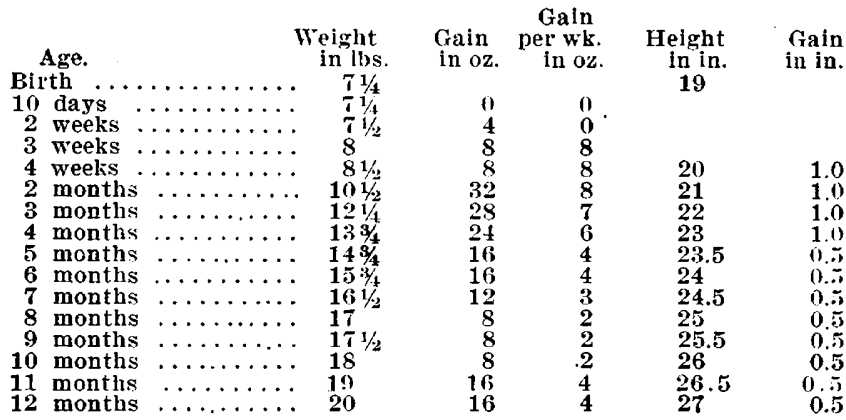

During the first three or four days the baby loses weight, from one or two ounces to ten or twelve. In Holt's series of one hundred the average initial loss was

1. Holt: Diseases of Infancy and Childhood. Griffith: The Care of the Baby. 